\title{
Educação em saúde reprodutiva: proposta ou realidade do Programa Saúde da Família?
}

\author{
Education in reproductive health: proposal \\ or reality in the Family Health Program?
}

Escolástica Rejane Ferreira Moura 1

Rosiléa Alves de Sousa 2

1 Secretaria da Saúde do Ceará. Av. Pessoa Anta s/n, Fortaleza, CE 60060-430, Brasil. escolastica@fortalnet.com.br 2 Maternidade Escola Assis Chateaubriand, Universidade Federal do Ceará. Rua Coronel Nunes de Melo s/n, Fortaleza, CE 60430-270, Brasil. rose_alves@hotmail.com

\begin{abstract}
As supervisors of primary health care units in the State of Ceará, Brazil, we have observed a low supply of health education services. As part of the activities under the Family Health Program (FHP), we attempted to investigate the causes of this short supply and identify flaws in the development of such activities. Interviews and participatory observation were adopted as the research method. The following causes were defined in the lack of health education practices: disorganization of demand, insufficient coverage of the population by FHP teams, resistance by both health professionals and the population to educational activities, absence of adequate floor space for conducting such activities, and lack of support materials. The following flaws were identified in the implementation of activities: limited exchange of experiences among participants; limited focus on the group's needs; frequent use of scientific language; transfer of outdated information; and inadequate utilization of teaching materials. The conclusion is that there is a need to retrain health professionals and to improve the availability of physical resources and teaching materials in order for education in reproductive health to become a reality in the FHP. Key words Health Education; Family Health Program; Reproductive Medicine
\end{abstract}

Resumo Considerando nossas percepções, enquanto supervisores de unidades primárias de saúde, no Ceará, de que há baixa oferta das ações de educação em saúde, como parte das atividades do Programa Saúde da Família (PSF), buscou-se investigar suas causas, bem como identificar as falhas no desenvolvimento dessas ações. Aplicou-se a entrevista e a observação participante como método de pesquisa. Detectou-se como causas do déficit das práticas educativas, a desorganização da demanda, a insuficiciente cobertura da população por equipes de PSF, a resistência dos profissionais e da população às ações educativas, a ausência de área física adequada para a realização das ações e escassez de material de apoio. Quanto às falhas no decorrer das atividades, identificou-se: pouca troca de experiências entre os participantes; orientação pouco direcionada às necessidades do grupo; uso freqüente de linguagem científica; repasse de informações desatualizadas e utilização inadequada do material de apoio. Conclui-se ser necessária a atualização dos profissionais de saúde, assim como uma disponibilização maior de recursos físicos e de material de apoio, para que a educação em saúde reprodutiva seja uma realidade no PSF. Palavras-chave Educação em Saúde; Programa Saúde da Família; Medicina Reprodutiva 


\section{Introdução}

Dentre os objetivos específicos do Programa Saúde da Família (PSF) podemos destacar a produção social da saúde, por meio da troca de informações e experiências entre as equipes de PSF e a comunidade, através da educação em saúde (COSAC, 1997). Para Levy (2000), a educação em saúde deve oferecer condições para que as pessoas desenvolvam o senso de responsabilidade, tanto por sua própria saúde, como pela saúde da comunidade, merecendo consideração como um dos mais importantes elos entre as perspectivas dos indivíduos, os projetos governamentais e as práticas de saúde. Nesse sentido, Kawamoto (1993) e Levy (2000) ressaltam que as ações educativas em saúde são processos que objetivam capacitar indivíduos e/ou grupos, de modo que possam assumir ou ajudar na melhoria das condições de saúde da população.

A partir das nossas vivências como supervisoras de unidades básicas de saúde do Ceará, identificamos o quanto é baixa a freqüência das atividades de educação em saúde desenvolvidas pelas equipes do PSF, e que, quando as realizam, fazem-nas de maneira verticalizada, com temas prontos, permitindo pouca ou nenhuma interação com a clientela. Percebemos, também, que a orientação individual oferecida por ocasião das consultas, restringe-se ao simples repasse de informações, denunciando problemas relacionados com a falta de conhecimentos, habilidades e atitudes dos profissionais à realização adequada dessa atividade. Collet \& Rosso (1999) revelam que na maioria das vezes, o enfermeiro atua como um mero repassador de informações, sem fazer uma reflexão da realidade local, levando em consideração as políticas oficiais de saúde.

A partir desse diagnóstico empírico, estabelecemos, como objetivos deste estudo, levantar as causas da baixa oferta das ações educativas realizadas pelas equipes de PSF e identificar as principais falhas no desenvolvimento dessas ações.

\section{Caminho metodológico}

Tomamos como universo dos dados deste trabalho, as unidades básicas de saúde da sede dos oito municípios que compõem a microrregião de saúde de Baturité (MR/4), a 4a das 21 que compõem o Estado do Ceará. Escolhemos a MR/4 por atuarmos como consultoras nessas unidades durante a implementação do Projeto de Qualidade (PROQUALI), que estabelece cri- térios mínimos para a garantia da qualidade, com seus respectivos meios de verificação, (Ceará, 1999). Os dados foram colhidos em julho de 1999 e em fevereiro de 2000, através da observação participante.

\section{Resultados}

Os resultados do trabalho estão apresentados em duas categorias: (1) oferta das atividades educativas, e condições físicas e de material de apoio à sua realização; e (2) falhas identificadas no desenvolvimento dos trabalhos com grupos.

\section{Categoria 1: oferta das atividades} educativas e condições físicas e de material de apoio à sua realização

Dos oito municípios, em apenas dois eram oferecidas atividades educativas com grupos. Constatamos, ainda que na maioria dos serviços, não existia uma sala apropriada à realização de atividades com grupos, de maneira que as sessões educativas observadas aconteceram em locais inadequados, com pouca ou nenhuma privacidade, ventilação e iluminação precárias, quantidade insuficiente de cadeiras e escassez de material de apoio (álbum seriado, cartilhas, folhetos e outros).

Os funcionários identificaram, como responsáveis pela pouca oferta de atividades educativas, os seguintes fatores: (1) a alta demanda de pessoas interessadas em consultas que deixa a equipe sem disponibilidade para o trabalho educativo. Por outro lado, a população, muitas vezes, mostra-se resistente à participação nas ações educativas, valorizando o aspecto curativo da assistência; (2) a cobertura, por equipes de PSF, não atinge $100 \%$ do município, gerando demandas reprimidas para a assistência na unidade de saúde e sobrecarregando os profissionais com atividades de assistência; (3) muitos dos profissionais, por não disporem de área física e de material de apoio para o desenvolvimento dessas atividades, não encontram motivação para executá-las e (4) outros profissionais afirmaram falta de habilidade para o trabalho com grupos, revelando timidez e inibição para o desenvolvimento dessa tarefa.

\section{Categoria 2: falhas identificadas no} desenvolvimento dos trabalhos com grupos

As atividades observadas foram realizadas por três enfermeiras e uma médica. Uma das enfermeiras não seguiu os critérios preconizados 
pelo projeto para as atividades de educação em saúde, o que mostrou a necessidade de aperfeiçoamento da profissional. As demais profissionais acolheram o grupo cordialmente e apresentaram-se, no entanto, não valorizaram o início da orientação pelo tema de maior relevância, não ofereceram informações corretas sobre os temas e utilizaram o material de apoio de forma inadequada. No que diz respeito à estimulação do grupo para fazer perguntas, houve prejuízo devido a utilização de perguntas fechadas e induzidas, que inibiram a participação das clientes. Via de regra, a linguagem utilizada foi clara, mesmo que, em determinados momentos, tenhamos percebido o uso de alguns termos de difícil compreensão para a comunidade.

Observamos que, em um dos municípios, durante as atividades de educação em saúde, a porta da sala manteve-se aberta. Esse fato foi bastante negativo e interferiu em vários aspectos do grupo: o barulho externo dificultou a escuta das informações e dispersou a atenção do grupo, enquanto que a falta de privacidade inibiu a participação e a troca de experiências.

\section{Conclusão}

Ao final deste estudo, podemos concluir que a baixa oferta de atividades de educação em saúde, na microrregião de saúde de Baturité, é decorrência de uma série de razões: a insuficiente cobertura da população por equipes de PSF, predomínio do modelo tradicional curativo, ausência ou inadequação de local para o desenvolvimento das atividades educativas, disponi-

\section{Referências}

ALMEIDA, M. I., 2001. Programa Saúde da Família: Significados e Imagens. Dissertação de Mestrado, Fortaleza: Faculdade de Farmácia, Odontologia e Enfermagem, Universidade Federal do Ceará.

COLLET, N. \& ROSSO, C. F. W., 1999. Os Enfermeiros e a Prática de Educação em Saúde em Municípios do Interior Paranaense. Outubro $2000<\mathrm{http}$ :// www.fen.ufg.br/revista>.

COSAC (Coordenação de Saúde da Comunidade), 1997. Programa Saúde da Família. Brasília: COSAC, Secretaria de Assistência à Saúde, Ministério da Saúde.

KAWAMOTO, E. E., 1993. Educação em saúde. In: Enfermagem Comunitária (E. E. Kawamoto, org.), pp. 29-33, São Paulo: E. P. U. bilização insuficiente de material de apoio e despreparo e desmotivação dos profissionais.

Os profissionais sentem-se pouco preparados para a realização dessas atividades. Inferimos, do que foi observado, que essa deficiência está associada à mudança de paradigma educativo, pois hoje, a prática educativa exige o conhecimento da realidade, além de uma visão crítica daqueles que se propõem a desenvolver qualquer temática, pois conforme Kawamoto (1993), a educação em saúde deve estar baseada na reflexão crítica do grupo quanto aos problemas e às ações necessárias à melhoria da qualidade de vida.

Acreditamos que o PSF oferece uma oportunidade ímpar para o desenvolvimento de atividades dessa natureza. Almeida (2001) recomenda a sistematização do componente educação em saúde, pelas equipes de PSF, sugerindo a aplicação de uma metodologia de educação popular, formando grupos de interesses comuns, oportunizando discussões com a comunidade e promovendo a aproximação dos profissionais com os movimentos sociais.

Lembramos que, para a realização da educação em saúde não são necessários o uso de vídeos e de outros materiais sofisticados. Se estes não estão disponíveis, a troca de idéias poderá ser enfatizada a partir da utilização de gravuras, recortes de jornal ou revista, materiais acessíveis na rotina de atendimento (por exemplo, o instrumental para exame ginecológico) e amostra de cada contraceptivo disponível. Dessa forma, a criatividade e o envolvimento do provedor com o seu público-alvo, podem ser fatores determinantes no sucesso das atividades de educação em saúde.
LEVY, S., 2000. Programa Educação em Saúde. Outubro $2000<$ http://www.saúde.gov.br/programas/ pes/pes/index.htm>.

SES-CE (Secretaria Estadual de Saúde do Ceará), 1999. Projeto de Melhoria da Qualidade (PROQUALI). Fortaleza: Célula de Saúde Reprodutiva e Sexual.

Recebido em 14 de maio de 2001

Versão final reapresentada em 12 de dezembro de 2001 Aprovado em 24 de maio de 2002 